\title{
Toll-Free Telephone Number
}

National Cancer Institute

\section{Source}

National Cancer Institute. Toll-Free Telephone Number. NCI Thesaurus. Code C43413.

A special telephone number in which the calling party is not charged for the cost of the call. Instead, the called party pays all of the charges for the call. 